\title{
Economics
}

The Open-Access, Open-Assessment E-Journal

Vol. 13, 2019-44 | October 28, 2019 | http://dx.doi.org/10.5018/economics-ejournal.ja.2019-44

\section{Limitations of stabilizing effects of fundamentalists: facing positive feedback traders}

\author{
Michael Heinrich Baumann, Michaela Baumann, \\ and Alexander Erler
}

\begin{abstract}
The authors analyze financial interactions between chartists with bounded leverage and fundamentalists within a heterogeneous agent model, focusing on the role of fundamentalists to stabilize prices. While many related studies are solely based on simulations, the authors analytically prove that the existence of fundamentalists is insufficient to avoid asset price bubbles for a certain setup of a feedback trader model. Moreover, similar studies very often face the criticism that chartists might run out of money before the emergence of bubbles, as these studies typically analyze the role of chartists with unbounded leverage. In the work at hand, however, the authors prove that even in an environment where chartists have limited access to finance, their investment behavior can lead to exploding prices. The chartists under study are so-called positive feedback traders, whose leverage is bounded. Additionally, the authors derive upper boundaries for positive feedback traders' initial investment necessary to avoid exploding prices. In order to stabilize stock/asset markets, intervention measures might be helpful.
\end{abstract}

JEL D84 G01 G11

Keywords Heterogeneous agents; feedback trading; fundamentalists; chartists; trend followers; financial bubbles; financial crisis

\author{
Authors \\ Michael Heinrich Baumann, Department of Mathematics and Department of \\ Economics, University of Bayreuth, Germany , michael.baumann@uni-bayreuth.de \\ Michaela Baumann, University of Bayreuth, Germany \\ Alexander Erler, University of Bayreuth, Germany \\ Citation Michael Heinrich Baumann, Michaela Baumann, and Alexander Erler (2019). \\ Limitations of stabilizing effects of fundamentalists: facing positive feedback traders. \\ Economics: The Open-Access, Open-Assessment E-Journal, 13 (2019-44): 1-25. \\ http://dx.doi.org/10.5018/economics-ejournal.ja.2019-44
}

Received October 5, 2018 Published as Economics Discussion Paper January 7, 2019 Revised August 31, 2019 Accepted September 27, 2019 Published October 28, 2019 


\section{Motivation and literature review}

Financial market bubbles have repeatedly caused macroeconomic threats, a very prominent example of which was the dot-com bubble. While misguided economic policies are typically among the usual suspects in trying to understand such aberrations, an important strand of the literature focuses on the question of whether specific behavior of market participants is responsible for price bubbles. In particular, heterogeneous agent models (HAMs) analyze how both chartists and fundamentalists are able to determine asset price movements (Hommes, 2006a).

Chartists, i.e., for instance, trend followers, trade based only on information about the price process, that is, they assume that all relevant information has already been priced in (cf. Graham et al., 1934). In contrast, fundamentalists have some fundamental value in mind and trade based on perceived over- or undervaluation of the underlying asset. Trend followers magnify the current trend, either positively or negatively, because their trading is based on the philosophy that the greater the absolute value of the slope of the price process, the more should be bought or sold (Covel, 2004). Fundamentalists, in contrast, buy or sell when the price is below or above the fundamental value, thereby pushing the asset price toward its fundamental value. Traders act out of self-interest with the intention of making a profit, and give little thought to how their actions will impact prices (Kim and Markowitz, 1989; Bornholdt, 2001). As a consequence of the two different investment strategies, the presence of chartists can cause exploding prices (De Long et al., 1990b), whereas fundamentalists are associated with a stabilizing influence on assets. Thus, the following question arises:

\section{Are the balancing effects of fundamentalists strong enough to compensate for the destabilizing impacts of chartists?}

Heterogeneous agent models are increasingly employed in search of an answer to this question (Gaunersdorfer and Hommes, 2007; Hommes, 2002; Lux, 1995, 1998; Lux and Marchesi, 1999, 2000). ${ }^{1}$ The models typically use bounded rational agents, (imperfect) heuristics or rules of thumb, and nonlinear dynamics (which might be chaotic). Some studies find that the stabilizing effects of fundamentalists are not necessarily strong enough to stabilize markets (Hommes, 2006a). However, the results are usually obtained via simulations and are not analytically proven (Hommes, 2006a,b). An exception is the work of De Long et al. (1990b) which investigates the effect of positive feedback traders and informed speculators, who evaluate and consider the needs of the other market participants, especially the growing needs of the positive feedback traders, in a three-period market model facing fundamentalists. De Long et al. (1990b) show that the interaction of these two trader types pushes the price away from the fundamental value under specific assumptions and despite the fundamentalists' stabilizing behavior. Our analysis differs from De Long et al. (1990b) in that we do not investigate how two types of traders-positive feedback traders and informed speculators-jointly push up the price but instead look only at trend followers, nor do we assume a predetermined end of the market. This leads us to a second question:

\footnotetext{
1 Additionally, these studies provide useful explanations for many stylized facts, such as excess and clustered volatility, high trading volume and the profitability of trend following, temporary bubbles and sudden crashes implying mean reversion, as well as fat tails in the returns' distributions. For an excellent overview regarding HAMs see the work of Hommes (2006a).
} 


\section{Is it possible to analytically prove that chartists' behavior can lead to exploding prices irrespective of fundamentalists' compensatory effects?}

As pointed out by, among others, Day and Huang (1990) and Huang and Day (1993), in elementary equilibrium models fundamentalists may not be sufficient to stabilize markets. However, all these papers are subject to the criticism that chartists will run out of money before prices become unstable. Therefore, in our analysis the leverage of the chartists is bounded, i.e., the ratio of invested money and wealth is limited. Precisely, the pricing rule and the behavior of fundamentalists is modeled similar to Day and Huang (1990) and Huang and Day (1993). In constrast to these authors, we use a different chartist rule: a strategy with bounded leverage. This enables us to overcome the criticism that chartists run out of money before prices become unstable. ${ }^{2}$ This leads us to the third research question:

\section{Is it possible to prove that chartists with bounded leverage can destabilize markets, regardless of the influence of fundamentalists?}

The main contribution of our paper is a mathematically rigorous proof that chartists' behavior can dominate the stabilizing effects of traders with rational expectations and without any liquidity constraints. Put differently, prices explode because the stabilizing effects of fundamentalists are outweighed by linear feedback traders, the specific type of chartists we use. Unstable price developments are the result, which in turn increase the likelihood of a financial bubble.

As shown in the proof, thresholds for model-inherent values can be specified to ensure the emergence of a bubble. Furthermore, there are certain values of external parameters that allow the thresholds of the inherent values to be met. The analysis reveals that even fundamentalists without any liquidity constraints and with perfect information about the price, the fundamental value, and the market's characteristics are insufficient to stabilize a very simply constructed market based on (excess) demand if the feedback trader's initial investment is large enough. The main reason for this behavior given in our work is that fundamentalists respond always one period later than chartists. This property is analytically shown. When fundamentalists could forecast and compensate the demand of the chartists, markets would always be stable. However, fundamentalists have to wait for the actions of the chartists and can therefore respond only with a delay of one period, giving the chartists the opportunity to raise prices, make profit, and invest even more.

Further important work on the topic of interactions between fundamentalists and chartists is done by Westerhoff (2004) who uses a very similar pricing rule as we do. The main difference is that the chartist's demand is assumed to be linear in the slope of the log-price. This leads to a possibly unbounded leverage, i.e., the ratio between assets and equity can go to infinity. In Westerhoff (2004) it is shown that price dynamics become unstable when the ratio between the chartist's and the fundamentalist's demand parameter becomes too large. However, in that model it is not clear whether the chartist can follow the "linear in the slope of the log-price" trading rule at all because the leverage is possibly unbounded.

\footnotetext{
2 Among others, Tramontana et al. (2010); Dieci and Westerhoff (2010); Brock and Hommes (1997, 1998); Tramontana et al. (2009); Lux (1995) rely on chartists with unbounded leverage and/or obtain results via simulations rather than via proofs.
} 
We explain the meaning of unbounded leverage in another setting: Let's have a look at doubling up strategies for roulette. It is easy to see that such a roulette strategy will almost surely lead to a positive payoff: the gambler bets on red until red wins and doubles the bet each time black wins. The problem is that the gambler might run out of money before realizing the gain.

In this analysis, the leverage of the chartist is bounded by the so-called feedback parameter $K$, which allows us to assume that the chartist can trade according to the chartist's rule, producing a bubble. That means, our analysis shows that regardless of the chartist's bounded leverage, technical trading might destabilize financial markets. Westerhoff (2004) uses a model where the demand parameters are fixed, i.e., in each point in time the dynamics are, despite of scaling, the same. Since the chartist in our model is a feedback trader with an investment depending on the chartist's gain, the demand of the chartist might be small for a long time before exploding. Nonetheless, our analysis provides a formula to check already in period zero whether the price path will eventually explode. $^{3}$

Other studies close to our work are Franke and Westerhoff $(2012,2016)$. However, Franke and Westerhoff $(2012,2016)$ apply an important feature: learning. Using so-called replicator dynamics, the share of chartists and fundamentalists in the model can change, i.e., traders learn from better performing market participants and adjust their rule. In that setting several stylized market facts can be reproduced. By contrast, we are less interested in stylized facts but more in the stability analysis of the market. In a market where fundamentalists can switch to chartist rules when this is more profitable, the likelihood of price bubbles is even higher. When there is an upwards trend in the chart, chartists will make profit and fundamentalists will switch to chartist rules. Thus, there are less fundamentalists who disinvest from the asset and more chartists who invest in the asset: so even more capital will be invested and prices will rise faster. In our model, we explicitly do not allow traders to switch because our aim is to show that not the replicator dynamics lead to the asset price bubble but the trading rules themselves do. Put differently, we show that prices might explode even when the shares of the traders are fixed and the leverage of the chartists is bounded.

In the works of Barmish and Primbs (2011, 2016); Baumann (2017); Baumann and Grüne (2017, 2019); Primbs and Barmish $(2013,2017)$ and the references therein many new results concerning technical trading strategies were found. For example, the performance properties of chartist strategies have been proven and explanations given for why it is reasonable to trade according to a feedback strategy. In contrast to the feedback trading literature, where the price taker property is usually presumed, we study the effects of trading strategies in an HAM that displays phenomena caused by excess demand (Baumann, 2015).

The paper is organized as follows: In Section 1 we formulated the research questions and discussed the relationship and differences to the literature dealing with agent-based models. In Section 2 we explain the model structure, i.e. the timeline and the price model. In Sections 3 and 4 we introduce the investment strategies of feedback traders and fundamentalists. In addition, we present the corresponding literature from which we have adopted the price model and the trading strategies of the fundamentalists and chartists and we state where we have made changes.

3 Other work in the area is done by Hermsen et al. (2010); Westerhoff (2006a,b, 2007); Westerhoff and Dieci (2006). Further related work is conducted by Beker (2010); Biondo (2018); Bormann (2013); Caccioli and Marsili (2010); Demary (2010); Krug (2018); Schasfoort and Stockermans (2017). 
We also discuss the assumptions behind the model structure. Furthermore, Section 3 presents some analytical findings from the literature dealing with feedback traders in the absence of fundamentalists in our market model. Since our analysis builds upon these findings, mathematical proofs are given as well. Section 5 contains the main contribution: we analytically prove that fundamentalists are not sufficient to stabilize markets when interacting with chartists with bounded leverage, i.e. with linear feedback traders. The main findings are summarized in Section 6.

\section{Model structure}

Our market model consists of a one asset market and is populated with two types of heterogeneous agents: fundamentalists and chartists. Their interaction with the market maker is illustrated in Section 2.1. Section 2.2 presents the price process in the interactive market model. The trading strategies are introduced in Sections 3 and 4. Section 4.2 additionally deals with the role of expectations. For simplifying the analysis we assume that there is only one feedback trader, that is we treat all existing feedback traders as one representative feedback trader. There is indeed no difference between one feedback trader with an initial investment $I_{0}^{C}$ and fixed $K$, see Section 3, and $n$ feedback traders with initial investments $\frac{I_{0}^{C}}{n}$ and the same $K$. That is, for the feedback traders this summarization is without loss of generality.

Note that our pricing rule is structurally similar to that one used by Day and Huang (1990); Huang and Day (1993) and analyses relying on these papers. The fundamentalists' rule (see Section 4) is a standard rule from this strand of literature as well. Our analysis differs from the literature in the way how chartists are modeled because we use linear feedback traders (see Section 3) to overcome the problem that chartists' leverage in the literature is unbounded. That means, our study is embedded in the related literature and emphasizes the results that fundamentalists might be unsuccessful to stabilize markets even in an environment with chartists facing limited access to finance.

\subsection{Timeline}

At the beginning of each period $t \in\{0,1, \ldots, T\}$, each agent $\ell \in\{C, F\}$, where $C$ is the feedback trader (chartist) and $F$ the fundamentalist, decides how to invest based on the respective investment strategy, where $T$ is unknown or even $\infty$. Each investment strategy $I_{t}^{\ell}$ is guided by a different heuristic (rule of thumb). Based on the strategy chosen, each agent then allocates his or her financial resources among the asset market. The trader is aware of historical market data and of expectations regarding future fundamental values $\mathbb{E}\left[f_{t+1}\right]$. The resulting buying and selling decisions, denoted by $D_{t}^{\ell}$, are cleared by a market maker who adjusts asset prices according to excess demand. After the traders have observed the price change $\Delta p_{t}$, and hence their own gains or losses $\Delta g_{t}^{\ell}$ in the recent period, they use this information in making their next investment decision.

Based on this trading behavior the price model is constructed. The timeline of the traders' and the market maker's decisions and interactions is shown in Figure 1. For all processes $\alpha_{t}$ we set $\Delta \alpha_{t}=\alpha_{t}-\alpha_{t-1}$ as the change of the underlying process, e.g., $\Delta g_{t}^{\ell}$ is the period profit while $g_{t}^{\ell}$ is the overall gain/loss of trader $\ell$. 
Figure 1: Timeline of the traders' and the market maker's decisions and interactions with $\Delta g_{t}^{\ell}=I_{t-1}^{\ell} \cdot \frac{\Delta p_{t}}{p_{t-1}}$

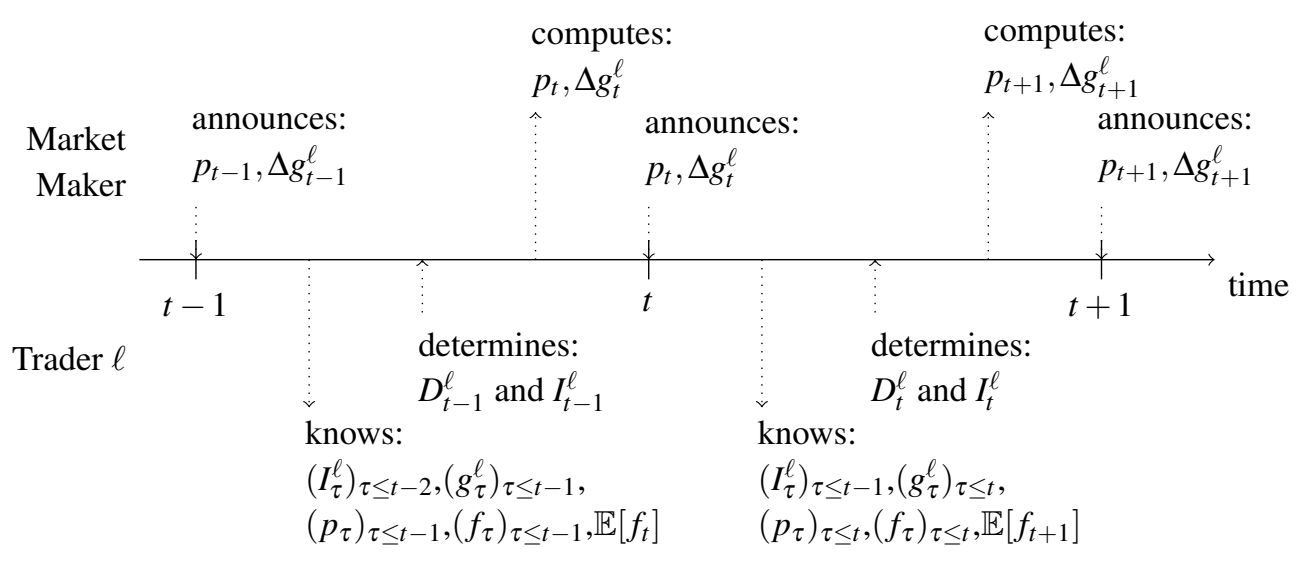

\subsection{Price process for the interactive market model}

In the feedback trading literature, prices are usually determined through a certain price process, for example, the geometric Brownian motion (GBM), which is exogenously given (Barmish and Primbs, 2016). This implies that the traders are not able to influence the price. To avoid this price taker property, which is a strong restriction of every market model, agent-based price models have evolved in the academic economics literature (Hommes, 2006a). According to these models, the price is a function of traders' investment decisions. We denote the sum of all traders' demand at time $t$ with $D_{t}=\sum_{\ell} D_{t}^{\ell}$. Based on the idea of interacting agents, Baumann (2015) constructs a pricing model that fulfills the law of excess demand, very similar to the following rules:

(i) $p_{t+1}=p_{t}$ if $D_{t}=0$

(ii) $p_{t+1} \rightarrow \infty$ if $D_{t} \rightarrow \infty$

(iii) $p_{t+1} \rightarrow 0$ if $D_{t} \rightarrow-\infty$

(iv) $p_{t+1}$ is strictly increasing in $D_{t}$

In fact, Baumann (2015) uses the change of investment $\Delta I_{t}$ instead of the demand $D_{t}$. Based on our simulations, using the change of investment instead of the demand (i.e., the buying/selling decision) affects the proposition of this paper only quantitatively, not qualitatively.

For simplification, we assume an infinite supply, and thus the law of supply and demand reduces to a law of (excess) demand. Infinite supply is, for example, given in artificial markets for synthetic assets, betting slips, etc. These assets are produced by the market maker without any restriction. Thus, the market maker can definitely clear the market. In modern stock exchanges, also shares of funds etc. can be bought from investment bankers (market makers) at any amount for a price set by the market maker. It follows that the market maker sets the new asset price according to the asset demand only. 
This model, which is in a sense a natural generalization of the GBM (proven in Baumann, 2015), in its general form is given by

$$
\begin{aligned}
p_{t+1} & =p_{t} \cdot e^{M^{-1} D_{t}} \\
& =p_{0} \cdot e^{M^{-1} B_{t}}
\end{aligned}
$$

where $M>0$ is a scaling factor expressing the trading volume of the underlying asset and

$$
B_{t}=\sum_{\tau=0}^{t} D_{\tau}
$$

is the sum of all demands up to time $t$. This pricing rule is similar to that one used by da Gama Batista et al. (2017). Unless otherwise stated, for simplicity $M$ is set to $M=1$. The pricing model is finally closed through the market maker (Hommes, 2006b). As common practice, the market maker acts as a privileged trader that sets prices according to (excess) demand (see Figure 2) and hence ensures market clearing (cf. the role of a broker in stock markets) (Hommes, 2006a). Possible profit making by and survival of the market maker will not be discussed in the work at hand but is an interesting topic for future work.

\section{Feedback traders}

In Section 2, we defined the timeline and the pricing model. As already explained, the model shall be populated with chartists and fundamentalists. For this reason, we first introduce chartists, in our case chartists with bounded leverage, namely linear feedback traders. In the current section, we not only motivate feedback traders, but also present results from the literature concerning market stability. These results from the literature are obtained under the assumption that in our market model only feedback traders would act. Since the new findings in this paper on the interaction between fundamentalists and feedback traders (i.e. Section 5) build upon this section on feedback traders, we also present the relevant proofs. Furthermore, it allows us to compare the results for the model with and without fundamentalists.

Barmish and Primbs (2011, 2016); Baumann (2017); Baumann and Grüne (2017, 2019); Primbs and Barmish $(2013,2017)$ outline a special class of trading strategies based on control techniques, namely, feedback trading. Traders engaged in this sort of strategy are called feedback traders and utilize neither fundamentals nor the absolute asset value in making their investments. They take into account only their own gains and losses. Their strategy thus depends on price changes relative to their previous investments. That is, feedback traders are chartists because gains or losses, respectively, are a function of the price but not of any fundamental value. From a control theoretic point of view, feedback traders treat the price like a disturbance variable and their strategy needs to be robust to this disturbing influence. In calculating a certain trader's gain, the market maker takes into account the trader's investment and the asset price. The price is a function of all traders' investments; see Section 2.2 and especially Figure 2. Therefore, in case of feedback traders it holds that investment decisions and gains are determined in a feedback loop. 
Figure 2: Schematic representation of the role of the market maker with $k$ traders

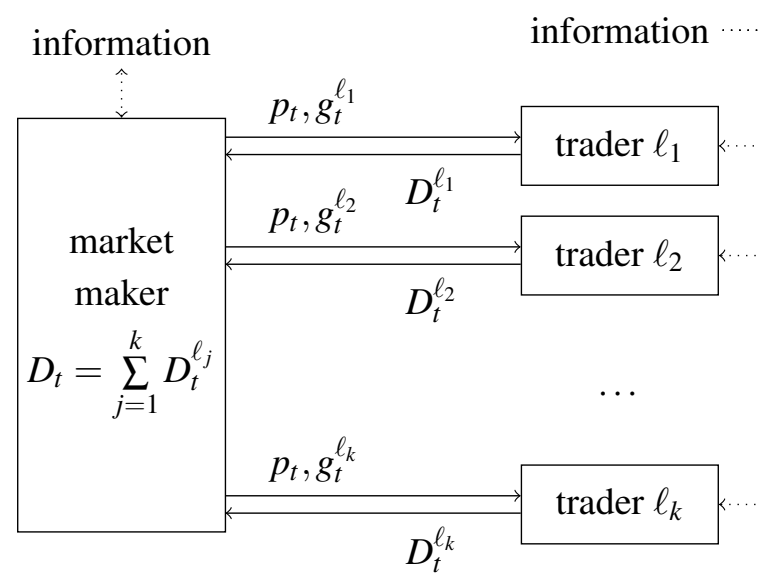

One specific feedback strategy discussed by Barmish and Primbs (2011, 2016); Baumann (2017) is the positive linear feedback strategy

$$
I_{t}^{C}:=I_{0}^{C}+K \cdot g_{t}^{C}
$$

where the linear feedback trader calculates the own investment $I_{t}^{C}$ at time $t$ as a linear function of the gain/loss function $g_{t}^{C}$ using the initial investment $I_{0}^{C}>0$ and a feedback parameter $K>0$. We rely on positive linear feedback strategies only because these are the feedback rules possibly causing financial bubbles. In Figure 3, a feedback loop between the gain or loss $g^{C}$ of a linear feedback trader and the respective investment $I^{C}$ is shown.

By calculating the gain or loss of a specific trader (or group of traders) $\ell$ via

$$
g_{t}^{\ell}=\sum_{i=1}^{t} I_{i-1}^{\ell} \cdot \frac{p_{i}-p_{i-1}}{p_{i-1}}
$$

where $p_{t}$ denotes the price process and $I_{t}^{\ell}$ the trader's investment at time $t$, it follows that linear feedback traders are trend followers given $I_{t}^{C}>0 .{ }^{4}$ A trader is called a trend follower (cf. Covel, 2004 ) if the trader is buying when prices are rising and selling when prices are falling. Note that the particular demand at time $t \geq 1$ is given by

$$
\begin{aligned}
D_{t}^{C} & =I_{t}^{C}-\frac{p_{t}}{p_{t-1}} I_{t-1}^{C} \\
& =I_{t-1}^{C}+K \cdot I_{t-1}^{C} \cdot \frac{p_{t}-p_{t-1}}{p_{t-1}}-\frac{p_{t}}{p_{t-1}} I_{t-1}^{C} \\
& =(K-1) \cdot I_{t-1}^{C} \cdot \frac{p_{t}-p_{t-1}}{p_{t-1}},
\end{aligned}
$$

\footnotetext{
4 The relative price change $\frac{p_{t}-p_{t-1}}{p_{t-1}}$ is called return on investment, and it is a specific feature of the chartist analyzed in the paper at hand that the chartist investment is a function of the return on investment.
} 
Figure 3: Schematic interaction between market maker and linear feedback trader information

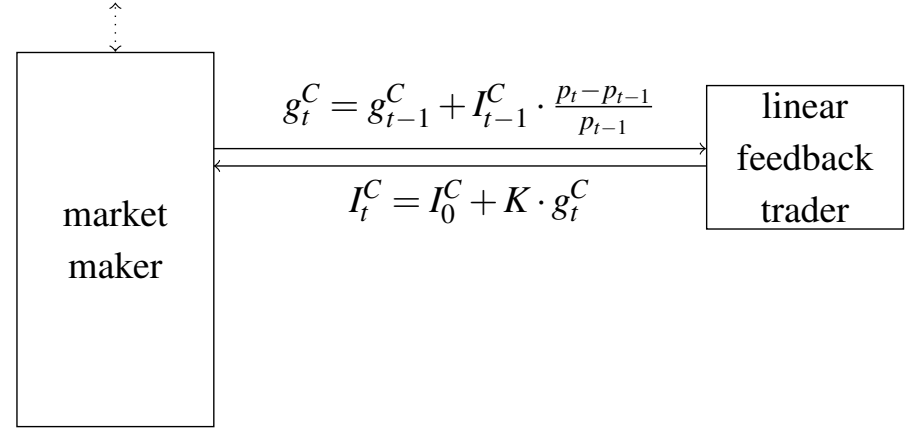

whereas $I_{t}^{C}$ denotes the total investment at time $t$ of feedback trader $C$. Note that

$$
\begin{aligned}
\Delta I_{t}^{C} & =I_{t}^{C}-I_{t-1}^{C} \\
& =I_{t-1}^{C}+K \cdot I_{t-1}^{C} \cdot \frac{p_{t}-p_{t-1}}{p_{t-1}}-I_{t-1}^{C} \\
& =K \cdot I_{t-1}^{C} \cdot \frac{p_{t}-p_{t-1}}{p_{t-1}} .
\end{aligned}
$$

This means that $D_{t}^{C}=\frac{K-1}{K} \cdot \Delta I_{t}^{C}$ and thus $B_{t}^{C}=\frac{K-1}{K} \cdot I_{t}^{C}$. If $K \neq 1$, the trader is not only a buy-and-hold trader, but is really buying and selling. We can rewrite

$$
D_{t}^{C}=K B_{t-1}^{C} \cdot \frac{p_{t}-p_{t-1}}{p_{t-1}} .
$$

Now, we always assume $K>1$, i.e., a trader who is buying more and more when making profit. This is the interesting case for bubble investigation. Note that the leverage of the chartist, i.e., the ratio of the money invested and the chartist's wealth, is bounded by $K$.

Rising prices lead to an increasing gain for the linear feedback trader if $I_{t}^{C}>0$ and, thus, the trader buys. Analogously, falling prices lower the gain and the trader sells.

In this section, for a later comparison, we study markets where only linear feedback traders act. That means, we set $I_{t}^{\ell} \equiv 0$ for all $\ell \neq C$. In this case, the feedback-based investment strategy is given by

$$
\begin{aligned}
& D_{0}^{C}=I_{0}^{C}>0, \\
& D_{1}^{C}=(K-1) \cdot I_{0}^{C} \cdot\left(e^{M^{-1} I_{0}^{C}}-1\right), \text { and } \\
& D_{t}^{C}=(K-1) \cdot I_{t-1}^{C} \cdot\left(e^{M^{-1} D_{t-1}^{C}}-1\right), t \geq 2 .
\end{aligned}
$$

This leads us to the following lemma.

Lemma 1. If in our market maker model there is only one trader, a linear feedback trader $C$, trading with the market maker, the price dynamics (for $t \geq 2$ ) is:

$$
\Delta B_{t}^{C}=K B_{t-1}^{C} \cdot\left(e^{\left.M^{-1} \Delta B_{t-1}^{C}-1\right)}\right.
$$


Baumann (2015) shows in a very similar model that in the event only one feedback trader $C$ is acting on the market with the price process described in Section 2, it holds that

$$
\begin{aligned}
& I_{t}^{C}>0 \forall t, \\
& D_{t}^{C}>0 \forall t, \text { and } \\
& D_{t}^{C}>D_{t-1}^{C} \Rightarrow D_{t+1}^{C}>D_{t}^{C} .
\end{aligned}
$$

We prove this in the remainder of this section.

Lemma 2. If the investments of all other traders are zero, the investment $I_{t}^{C}$ and the demand function $D_{t}^{C}$ of the linear feedback trader are positive.

Proof. The lemma is proven by induction. Because of $I_{0}^{C}>0$ and $e^{M^{-1} I_{0}^{C}}>1$, the initial inequality $D_{1}^{C}>0$ is true. It follows $I_{1}^{C}=I_{0}^{C}\left(e^{M^{-1} I_{0}^{C}}-1\right)+D_{1}^{C}>0$. The induction step follows, as $e^{M^{-1} D_{t-1}^{C}}>1$ and $I_{t}^{C}=I_{t-1}^{C}\left(e^{M^{-1} D_{t-1}^{C}}-1\right)+D_{t}^{C}>0$.

It holds that $D_{t}^{C}>0$ because of $I_{0}^{C}>0$. This means that feedback traders' investment increases prices and thus also their gain, leading again to positive buying decisions and so on. But this does not necessarily have to end in a bubble. We say that a bubble occurs if $\exists t^{*}: \Delta \ln p_{t+1}>$ $\Delta \ln p_{t} \forall t \geq t^{*}$. Note that if there are only chartists it holds that $p_{t}=p_{t-1} e^{M^{-1} D_{t-1}^{C}}$, i.e., $\Delta p_{t}=$ $p_{t-1}\left(e^{M^{-1} D_{t-1}^{C}}-1\right)$. Two typical demand paths can be identified in the scenario where only one feedback-based trader is acting on the market. The two paths are shown in Figure 4 and Figure 5 where the asset price $p_{t}$ is indicated with a solid line and the feedback trader's investment with a dashed one. If $I_{0}^{C}$ lies below a specific threshold, $I_{t}^{C}$ converges (Figure 4). If it is above this threshold, the investment explodes (Figure 5). Baumann (2015) provides a non-closed formula determining upper boundaries for this threshold. Specific values for this threshold can be derived through a simulation like that one in Figure 4 and Figure 5 and by algorithmically localizing the threshold. That means, the demand function and, thus, the price can converge to some value.

Theorem 3. If the investments of all other traders are zero and $\exists t^{*} \in \mathscr{T}: \Delta D_{t^{*}}^{C}>0$ then

$$
\Delta D_{t}^{C}>0
$$

holds for all $t \geq t^{*}$. That means, the bought amount of stocks $D_{t}^{C}$ of the feedback trader is strictly increasing for all $t \geq t^{*}$.

Proof. The induction step

$$
D_{t}^{C}>D_{t-1}^{C} \Rightarrow D_{t+1}^{C}>D_{t}^{C}, t \geq 1,
$$

has to be shown. This is true because of

$$
D_{t+1}^{C}>D_{t}^{C} \Leftrightarrow I_{t}^{C} \cdot\left(e^{M^{-1} \cdot D_{t}^{C}}-1\right)>I_{t-1}^{C} \cdot\left(e^{M^{-1} \cdot D_{t-1}^{C}}-1\right),
$$

$D_{t}^{C}>0$ from which it follows $\Delta I_{t}^{C}>0$ and the induction hypothesis. 
Figure 4: A typical situation in a market involving a feedback trader. The price (solid line) and the feedback trader's demand (dashed line) converge, i.e., the feedback trader's initial investment $I_{0}^{C}$ is below a specific threshold. Parameters: $p_{0}=1, M=1, T=250, I_{0}^{C}=0.191, K=2$

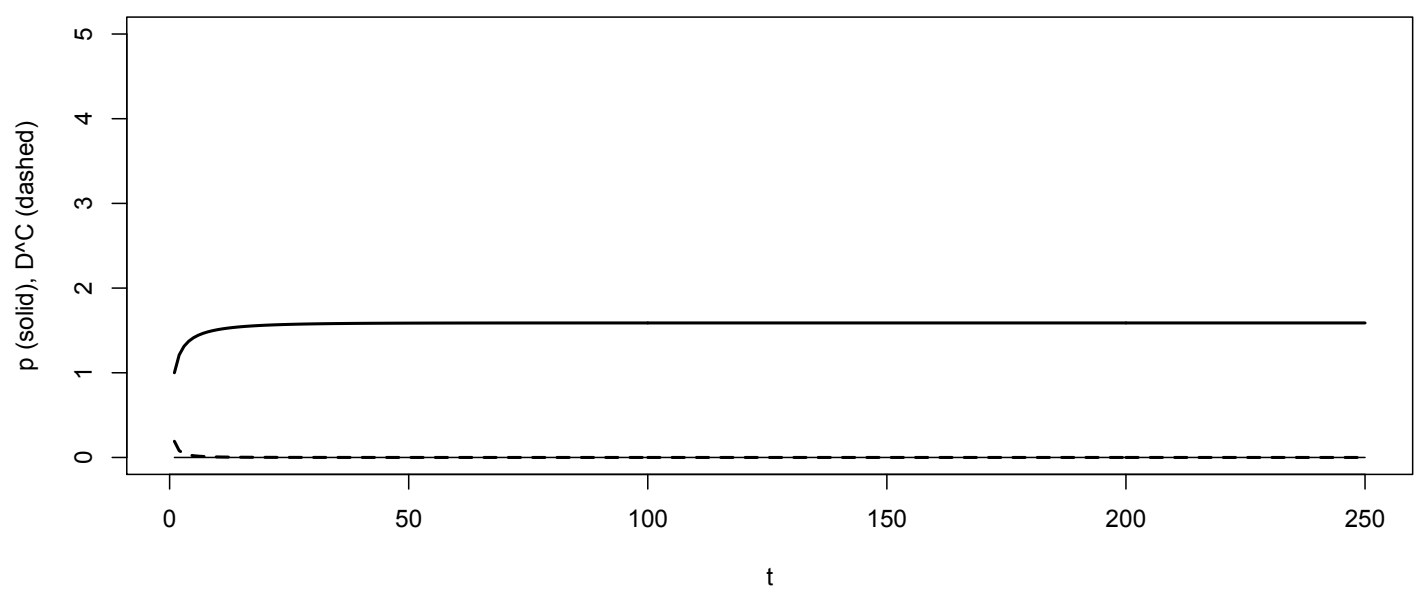

This is important as it is shown that, together with the results of Section 5, the price explosion effects of feedback traders that would possibly occur in absence of fundamentalists can be compensated by fundamentalists at least to a certain degree.

There remains the question why a trader should follow such a linear feedback trading strategy. The answer lies in some performance properties of feedback rules, especially of combinations of different linear feedback rules. For the performance analysis of feedback rules we refer to the work of Barmish and Primbs (2011, 2016); Baumann (2017); Baumann and Grüne (2017). ${ }^{5}$

\section{Fundamentalists}

In Section 3 we saw that feedback traders, i.e., chartists with bounded leverage, might destabilize markets in the absence of fundamentalists. The aim of our analysis is to analyze whether fundamentalists are able to compensate for these destabilizing effects. For this purpose, we introduce fundamentalists in Section 4.1, i.e., we formulate and motivate their trading strategy. When dealing with fundamentals, the importance of expectations is often mentioned. For this reason, in Section 4.2 we discuss the role of fundamentalists' expectations.

5 In the literature, a specific superposition of two linear feedback rules-the so-called simultaneously long short (SLS) strategy - is analyzed. It is shown that the SLS rule offers an arbitrage opportunity when prices are smooth and a positive expected gain when prices are governed by geometric Brownian motions, by Merton's jump diffusion model, and by many other price models. 
Figure 5: Another typical situation in a market involving a feedback trader only. The price (solid line) and the feedback trader's demand (dashed line) diverge, i.e., the feedback trader's initial investment $I_{0}^{C}$ is above a specific threshold. Parameters: $p_{0}=1, M=1, T=250, I_{0}^{C}=0.192, K=2$

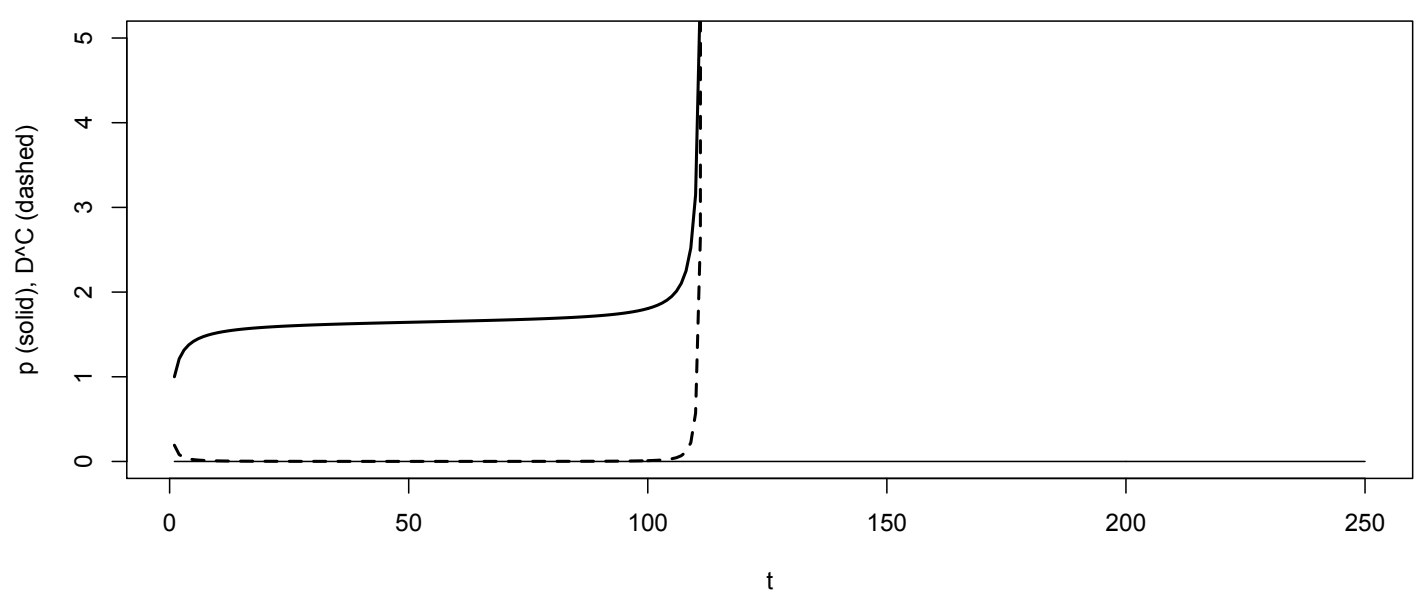

\subsection{Trading strategy of fundamentalists}

As explained in Section 1, fundamentalists buy when the price is below the fundamental value $f_{t}>0$ and sell when the price is above the fundamental value. If, for example, the fundamental value is below the asset price, fundamentalists conclude that the price decreases in the long run, not necessarily in the next step. So they possibly do not sell as much that their investment becomes negative, but they reduce their investment. Thus, it is of particular interest how much fundamentalists buy or sell in the respective cases. For deterministic fundamental values $f_{t}$, i.e., the fundamental value is a function in $t$, one way of determining the demand rate of the fundamentalists is

$$
D_{t}^{F}=M \cdot \ln \frac{f_{t+1}}{p_{t}}
$$

(cf. Drescher and Herz, 2012). In this case, fundamentalists do not need to estimate the fundamental value because it is fixed and certain for the future period. Note that we treat all fundamentalists as one representative fundamentalist. Traders following this demand rule could be called strong fundamentalists because their investment strategy could push the price back to its fundamental value at any time.

Theorem 4. If the strong fundamentalist is the only trader buying/selling at time $t$, then for any $p_{t}>0$ and $f_{t+1}$ it follows:

$$
p_{t+1}=f_{t+1}
$$


Proof.

$$
\begin{aligned}
p_{t+1} & =p_{t} \cdot e^{\ln \frac{f_{t+1}}{p_{t}}} \\
& =p_{t} \cdot \frac{f_{t+1}}{p_{t}} \\
& =f_{t+1}
\end{aligned}
$$

Note that our trading rule for fundamentalists is structurally similar to, among others, Huang and Day (1993); Day and Huang (1990); Drescher and Herz (2012). Section 4.2 presents the case of a fundamentalist trading based on a distorted fundamental value. It turns out, however, that this distortion does not affect the general behavior of the market model. Note that the leverage of the fundamentalists - in contrast to that one of the chartists-is assumed to be unbounded, i.e., the fundamentalists can buy and sell whatever they want independent of their account value.

\subsection{Expectations and noise}

Some types of traders, for example informed speculators (De Long et al., 1990b), base their trading decisions on rational expectations. Is this the case for feedback traders and fundamentalists?

In general, for feedback traders and trend followers, the answer is "no," as they only assume the existence of a trend. For example, based on the current slope of the asset price development $\left(p_{t}-p_{t-1}\right)$ they forecast the future direction of the asset. However, fundamentalists are assumed to have rational expectations (see, e.g., Drescher and Herz, 2012). Generally, they pursue the strategy

$$
D_{t}^{F}=M \cdot \ln \frac{\mathbb{E}\left[f_{t+1} \mid \mathscr{F}_{t}\right]}{p_{t}} .
$$

A casual observation of real markets makes clear that price fluctuations are not always purely rational. There is always noise and uncertainty in the market, a factor considered essential by many economists (see, e.g., Black, 1986; De Long et al., 1990a). Some reasons for noise include that traders make mistakes, trade on unreliable (noisy) information, or simply enjoy trading and are not overly concerned with being rational about it.

Here, we do not assume that traders are making mistakes, as this could lead to unsystematic behavior, i.e., we do not take noise traders into account. ${ }^{6}$ Furthermore, both feedback traders and fundamentalists do follow a specified strategy. Thus, the only way noise could enter the market is through noisy information. However, the traders' investments as well as the price, announced by the market maker (see Figure 1), are not distorted. The only information that could be noisy is that about the fundamental value. In this case, the fundamentalist has to estimate $f_{t+1}$ at time $t$ and trades according to $\mathbb{E}\left[f_{t+1} \mid \mathscr{F}_{t}\right]$. Since it is unreasonable that $\left|f_{t+1}-\mathbb{E}\left[f_{t+1} \mid \mathscr{F}_{t}\right]\right|$ becomes arbitrarily large, i.e., that the estimation of the fundamental value is totally wrong, but exploding prices imply $\left|p_{t}-f_{t}\right| \rightarrow \infty$, the effects of noisy information do not play a decisive role. Therefore, we a priori consider $f_{t}$ a deterministic fundamental value.

6 A market with a linear feedback trader and a noise trader is analyzed by Baumann (2015). 


\section{Proof of limitations of fundamentalists' stabilizing effects}

In this section, we demonstrate analytically and mathematically rigorously that fundamentalists are not always able to stabilize markets through their trading actions. We inductively prove, in contrast to simulations, that effects of linear feedback traders dominate those of fundamentalists and destabilize markets.

Since we already defined the pricing model and the traders, the next task is to check whether fundamentalists defined according to Section 4 are able to stabilize the price when trading simultaneously with linear feedback traders following the strategy presented in Section 3. As mentioned before, our pricing rule as well as the fundamentalists' trading rule are similar to that one used by Day and Huang (1990); Huang and Day (1993). We differ from these papers by using linear feedback traders as chartists, i.e., we use chartists with bounded leverage. Because the linear feedback trading rule is more complex than chartist rules with demand linear in log-price changes, we cannot analyze the price behavior by means of equilibria and stability considerations. Instead we rely on inductive proofs.

To simplify the notation, we set $f_{t} \equiv 1$. This is one special case, but when we can show the destabilizing effects of feedback traders' investment strategy for this case, it proves that fundamentalists do not always have market stabilizing effects. The proof proceeds without using technical trading restrictions.

In this section, we show that prices explode for appropriately chosen parameters $I_{0}^{C}$ and $K$ of linear feedback traders even when acting on a market with fundamentalists. Note that the fundamentalists are employing an investment strategy that could bring prices close to the fundamental value at every point in time. Thus, there is strong evidence that chartists' rules, in this case the linear feedback strategy, are able to overcome the effects of strong fundamentalists in various market situations. Hence, the two trader types linear feedback trader $C$ with bounded leverage and fundamentalist $F$ are suitable for analyzing the question of destabilizing effects of linear feedback traders.

Trend followers invest a lot when prices rise strongly and fundamentalists disinvest a lot when the price greatly exceeds the fundamental value, i.e., when prices explode, the investment of trend followers goes to infinity and the investment of fundamentalists goes to minus infinity. For traders who neither predicate their investment on the distance between the fundamental value and the price nor on the slope of the price it is unreasonable that their investment goes to (minus) infinity. Compared to the exploding investments of feedback traders and fundamentalists, the relatively small investments of possible other traders may be neglected at least for our analysis. Thus, it is enough to consider only linear feedback traders and fundamentalists and no other types of traders, some of which are presented by Ivanova et al. (2014).

Simulations reveal two typical price developments (see Figure 6 and Figure 7). In Figure 6, fundamentalists' effects predominate and the price stabilizes around the fundamental value. In Figure 7, however, market development is not that obvious. At a first glance, the figure might suggest that prices explode. But as the simulation software reaches its limits, it becomes unclear whether or not prices level out in these simulation scenarios. We therefore need an analytical examination. In cases like those shown in the simulated Figure 7, the proposition of Theorem 8 
Figure 6: A typical situation in a market involving a feedback trader and a fundamentalist. The price (solid line), the feedback trader's demand (dashed line), and the fundamentalist's demand (dotted line) converge, i.e., the fundamentalist's effects predominate since the trend follower's initial investment $I_{0}^{C}$ is below a specific threshold. Parameters: $p_{0}=1, M=1, T=25, f_{t} \equiv 1, I_{0}^{C}=5.19, K=2$

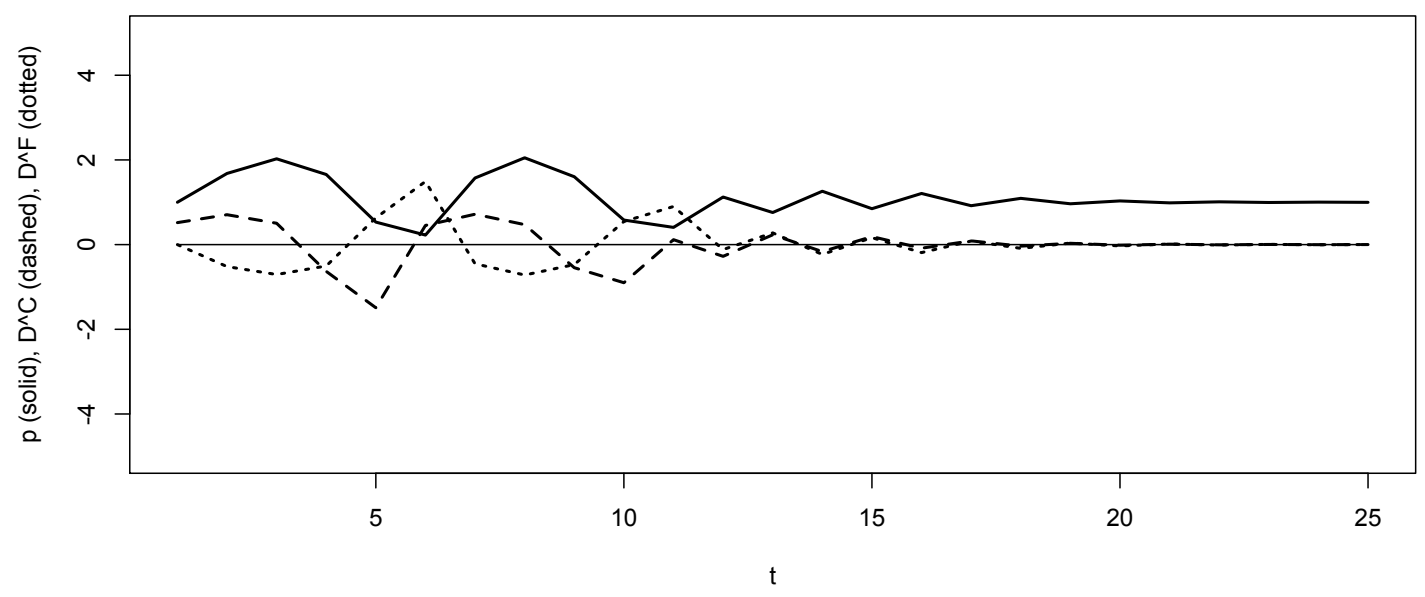

determines with certainty whether the bought amount of assets of the feedback traders is in fact exploding, or whether this only seems to be the case due to simulation insufficiencies and the portfolio eventually stabilizes, but with a greater amplitude as, for example, in Figure 6.

To simplify the expressions in the model, we assume in addition to $f_{t} \equiv 1$ that $p_{0}=1$ in all upcoming equations. This choice is just one possible scaling but does not change the model's dynamics in general. We define a process $\alpha_{t}$ as $\left(\alpha_{t}\right)_{t \in \mathbb{Z}} \subset \mathbb{R}$ with $\alpha_{t}=0 \forall t<0$. Furthermore, we define the $\Delta$-operator as $\Delta^{k} \alpha_{t}:=\Delta^{k-1} \alpha_{t}-\Delta^{k-1} \alpha_{t-1}, \Delta^{1} \alpha_{t}:=\Delta \alpha_{t}=\alpha_{t}-\alpha_{t-1}$, and $\Delta^{0} \alpha_{t}:=\alpha_{t}$. A price process $p_{t}$ is strictly positive, i.e., $\left(p_{t}\right)_{t}>0$ for all $t \geq 0$.

Theorem 5. In a market with one feedback trader $C$ and one fundamentalist $F$, it holds:

$$
D_{t}^{F}=-D_{t-1}^{C}
$$

That means, fundamentalists always compensate what chartists did one period before. Put differently, fundamentalists' reactions are one period delayed to the actions of trend followers, and in case of a bubble, the reactions are one period too late. It is worth mentioning here that the relation $D_{t}^{F}=-D_{t-1}^{C}$ is not an assumption but an analytical finding. The underlying assumption of Theorem 5, however, can be characterized as follows: We assume that trend followers base their investment strategy on the price trend and that fundamentalists use the difference between the fundamental value and the market price to calculate their respective strategy. Based on this assumption, we mathematically prove that fundamentalists react too slow to stabilize market prizes. On the contrary, if one would assume that fundamentalists would be predictive with $D_{t}^{F}=-D_{t}^{C}$, 
Figure 7: Another typical situation in a market involving a feedback trader and a fundamentalist. The price (solid line), the feedback trader's demand (dashed line), and the fundamentalist's demand (dotted line) diverge, i.e., the feedback traders' effects predominate since the feedback trader's initial investment $I_{0}^{C}$ is above a specific threshold. Parameters:

$$
p_{0}=1, M=1, T=25, f_{t} \equiv 1, I_{0}^{C}=0.521, K=2
$$

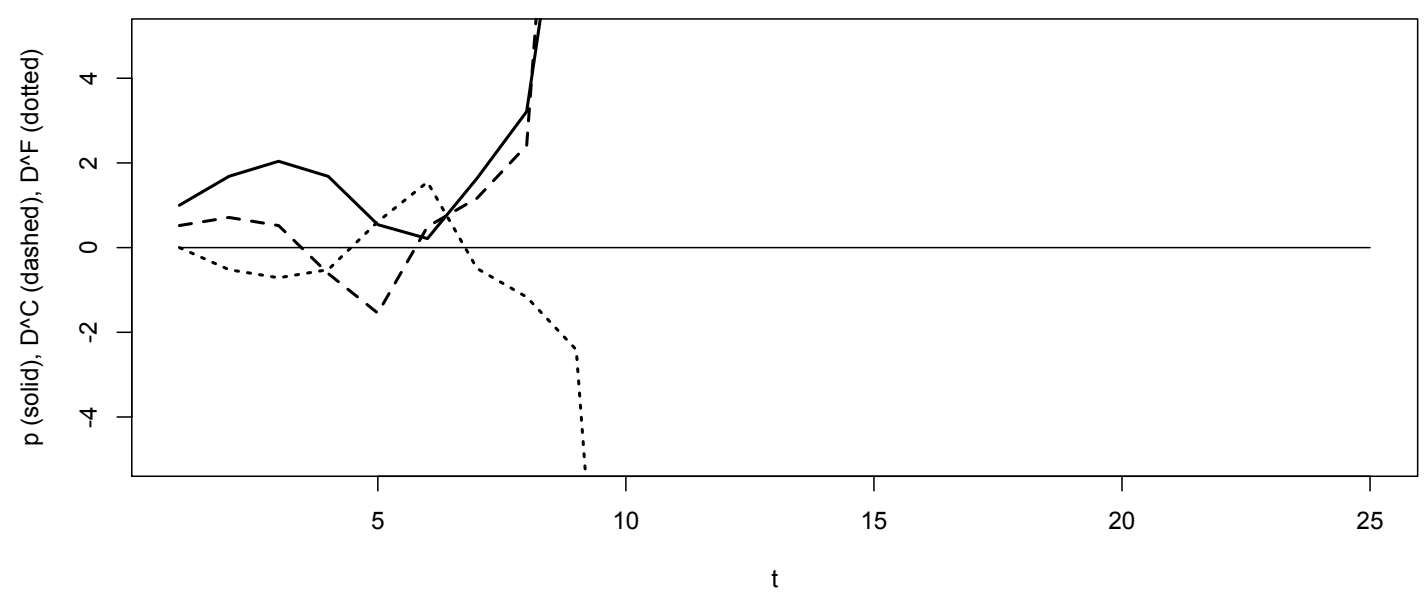

any bubble would presumably be prevented. Additionally, it would imply that fundamentalists would neither look at the price nor at the fundamental value, but would correctly anticipate the strategy of the trend followers in order to successfully offset the price changes induced by this type of investor. From our point of view, such an assumption would be in stark contrast to the findings of the literature on fundamentalists presented in our literature review.

Proof. We calculate:

$$
\begin{aligned}
D_{t}^{F} & =M \cdot \ln \frac{f_{t+1}}{p_{t}} \\
& =-M \cdot \ln e^{M^{-1} B_{t-1}} \\
& =-B_{t-1} \\
& =-B_{t-1}^{C}-B_{t-1}^{F} \\
\Rightarrow B_{t}^{F} & =-B_{t-1}^{C} \\
\Rightarrow D_{t}^{F} & =-D_{t-1}^{C}
\end{aligned}
$$


With Theorem 5, we can specify the demand of the feedback traders:

$$
\begin{aligned}
D_{t}^{C} & =K \cdot B_{t-1}^{C}\left(e^{M^{-1}\left(D_{t-1}^{C}+D_{t-1}^{F}\right)}-1\right) \\
& =K \cdot B_{t-1}^{C}\left(e^{M^{-1}\left(D_{t-1}^{C}-D_{t-2}^{C}\right)}-1\right) \\
& =K \cdot B_{t-1}^{C}\left(e^{M^{-1} \Delta D_{t-1}^{C}}-1\right)
\end{aligned}
$$

Lemma 6. If there are exactly one linear feedback trader $C$ and one fundamentalist $F$ trading with the market maker, it holds:

$$
\Delta B_{t}^{C}=K \cdot B_{t-1}^{C}\left(e^{M^{-1} \Delta^{2} B_{t-1}^{C}}-1\right)
$$

Theorem 8 tells us conditions for the feedback trader's cumulated demand $B^{C}$ for which prices explode. Note that the following implication holds:

\section{Lemma 7.}

$$
\Delta^{k} \alpha_{t-1}>a \wedge \Delta^{k+1} \alpha_{t}>b \Rightarrow \Delta^{k} \alpha_{t}>a+b
$$

We obtain this directly from the definition of the delta operator which is equivalent to

$$
\Delta^{k} \alpha_{t}=\Delta^{k+1} \alpha_{t}+\Delta^{k} \alpha_{t-1} .
$$

Note that $D_{t}^{C}=\Delta B_{t}^{C}$ and analogously for the derivatives.

Theorem 8. For the demand function resp. for the bought and sold assets of the positive linear feedback trader interacting with a strong fundamentalist on our market model, under conditions

$$
\Delta^{3} B_{t}^{C}>M \cdot \ln 2,
$$

$$
\Delta^{2} B_{t}^{C}>M \cdot \ln 2,
$$

$$
\Delta B_{t-1}^{C}>0, \text { and }
$$

$$
B_{t-2}^{C}>0
$$

for some $t \geq 2$ it follows that

$$
\Delta^{k} B_{t+1}^{C}>M \cdot \ln 2 \forall k \in\{0,1,2,3\} .
$$


Theorem 8 is proven by induction in the following.

Proof. It is enough to prove the proposition for $k=3$ as all other inequalities can then be derived from the definition of the $\Delta$-operator and Lemma 7 .

$$
\begin{aligned}
& \frac{1}{K} \Delta^{3} B_{t+1}^{C}=\frac{1}{K}\left(\Delta^{2} B_{t+1}^{C}-\Delta^{2} B_{t}^{C}\right) \\
& =\frac{1}{K}\left(\Delta B_{t+1}^{C}-2 \Delta B_{t}^{C}+\Delta B_{t-1}^{C}\right) \\
& =B_{t}^{C}\left(e^{M^{-1} \Delta^{2} B_{t}^{C}}-1\right) \\
& -2 B_{t-1}^{C}\left(e^{M^{-1} \Delta^{2} B_{t-1}^{C}}-1\right) \\
& +B_{t-2}^{C}\left(e^{M^{-1} \Delta^{2} B_{t-2}^{C}}-1\right) \\
& =\left(B_{t-2}^{C}+\Delta B_{t-1}^{C}+\Delta B_{t}^{C}\right)\left(e^{M^{-1} \Delta^{2} B_{t}^{C}}-1\right) \\
& -2\left(B_{t-2}^{C}+\Delta B_{t-1}^{C}\right)\left(e^{M^{-1} \Delta^{2} B_{t-1}^{C}}-1\right) \\
& +B_{t-2}^{C}\left(e^{M^{-1} \Delta^{2} B_{t-2}^{C}}-1\right) \\
& =B_{t-2}^{C}\left(e^{M^{-1} \Delta^{2} B_{t}^{C}}-1\right) \\
& +\Delta B_{t-1}^{C}\left(e^{M^{-1} \Delta^{2} B_{t}^{C}}-1\right) \\
& +\Delta B_{t}^{C}\left(e^{M^{-1} \Delta^{2} B_{t}^{C}}-1\right) \\
& -2 B_{t-2}^{C}\left(e^{M^{-1} \Delta^{2} B_{t-1}^{C}}-1\right) \\
& -2 \Delta B_{t-1}^{C}\left(e^{M^{-1} \Delta^{2} B_{t-1}^{C}}-1\right) \\
& +B_{t-2}^{C}\left(e^{M^{-1} \Delta^{2} B_{t-2}^{C}}-1\right) \\
& =B_{t-2}^{C}\left(e^{M^{-1} \Delta^{2} B_{t}^{C}}-2 e^{M^{-1} \Delta^{2} B_{t-1}^{C}}+e^{M^{-1} \Delta^{2} B_{t-2}^{C}}\right) \\
& +\Delta B_{t-1}^{C}\left(e^{M^{-1} \Delta^{2} B_{t}^{C}}-2 e^{M^{-1} \Delta^{2} B_{t-1}^{C}}+1\right) \quad(* *) \\
& +\Delta B_{t}^{C}\left(e^{M^{-1} \Delta^{2} B_{t}^{C}}-1\right) \quad(* * *)
\end{aligned}
$$


We evaluate these summands separately:

$$
\begin{aligned}
& (* *)=\Delta B_{t-1}^{C}\left(e^{M^{-1} \Delta^{2} B_{t-1}^{C}+M^{-1} \Delta^{3} B_{t}^{C}}-2 e^{\left.M^{-1} \Delta^{2} B_{t-1}^{C}+1\right)}\right. \\
& =\Delta B_{t-1}^{C}\left(e^{M^{-1} \Delta^{2} B_{t-1}^{C}}\left(e^{M^{-1} \Delta^{3} B_{t}^{C}}-2\right)+1\right) \\
& >\Delta B_{t-1}^{C}\left(e^{M^{-1} \Delta^{2} B_{t-1}^{C}}(2-2)+1\right) \\
& >0 \\
& (* * *)=\left(\Delta B_{t-1}^{C}+\Delta^{2} B_{t}^{C}\right)\left(e^{M^{-1} \Delta^{2} B_{t}^{C}}-1\right) \\
& >0+M \cdot \ln 2 \\
& (*)=B_{t-2}^{C}\left(e^{M^{-1} \Delta^{2} B_{t-2}^{C}+M^{-1} \Delta^{3} B_{t-1}^{C}+M^{-1} \Delta^{3} B_{t}^{C}}\right. \\
& \left.-2 e^{M^{-1} \Delta^{2} B_{t-2}^{C}+M^{-1} \Delta^{3} B_{t-1}^{C}}+e^{M^{-1} \Delta^{2} B_{t-2}^{C}}\right) \\
& =B_{t-2}^{C} e^{M^{-1} \Delta^{2} B_{t-2}^{C}}\left(e^{M^{-1} \Delta^{3} B_{t-1}^{C}}\left(e^{M^{-1} \Delta^{3} B_{t}^{C}}-2\right)+1\right) \\
& >B_{t-2}^{C} e^{M^{-1} \Delta^{2} B_{t-2}^{C}}\left(e^{M^{-1} \Delta^{3} B_{t-1}^{C}}(2-2)+1\right) \\
& =B_{t-2}^{C} e^{M^{-1} \Delta^{2} B_{t-2}^{C}} \\
& >0
\end{aligned}
$$

As a result, we obtain

$$
K^{-1} \Delta^{3} B_{t+1}^{C}>M \cdot \ln 2
$$

and since $K>1$

$$
\Delta^{3} B_{t+1}^{C}>M \cdot \ln 2
$$

This means, the feedback trader's bought and sold assets, the demand, the slope of the demand, and the curvature of the demand are strictly greater than $M \cdot \ln 2$ for all $t \geq t^{*}$ for some $t^{*}$. All in all, this is a fast exploding demand, which leads to an equally quickly exploding price.

$$
\begin{aligned}
p_{t+1} & =p_{t} \cdot e^{M^{-1} \cdot\left(D_{t}^{F}+D_{t}^{C}\right)} \\
& =p_{t} \cdot e^{\ln \frac{f_{t+1}}{p_{t}}} \cdot e^{M^{-1} \cdot D_{t}^{C}} \\
& =f_{t+1} \cdot e^{M^{-1} \cdot D_{t}^{C}}
\end{aligned}
$$

Theorem 9. If there are exactly one fundamentalist $F$ and one chartist $C$ (a linear long feedback trader), the price dynamics satisfies for $t>0$ :

$$
p_{t}=f_{t} e^{M^{-1} D_{t-1}^{C}}
$$


Recall that $D_{t}^{\ell}=\Delta B_{t}^{\ell}$. As an interpretation, note that since $D_{t}^{F}=-D_{t-1}^{C}$ (cf. Theorem 5 and its proof), fundamentalists always respond one period later with minus the demand of the feedback traders. Theorem 8 tells us that the feedback trader's cumulated demand increases, the demand itself increases, and the first and second derivative increase, too. Furthermore, all of these growth rates are bounded from below. Since the fundamentalist's demand is minus the demand of the feedback trader from one period before, the ratio of the bought and sold amounts is strictly increasing, that is the feedback trader's exploding effect predominates the fundamentalist's stabilizing one.

That the conditions for the endogenous variables of Theorem $8, B_{t-2}^{C}, \Delta B_{t-1}^{C}, \Delta^{2} B_{t}^{C}, \Delta^{3} B_{t}^{C}$, may be fulfilled for some $t$ (and some parameter assignment) is shown in Table 1 in which the demand development of the feedback trader is listed for $I_{0}^{C}=0.521, K=2$, and $M=1$. In short, there are exogenous variables that lead to a price explosion. This demonstrates that feedback traders' effects are able to overcome fundamentalists' effects.

On the other hand, Table 2 sets out a situation where the price would explode when only feedback traders are acting on the market. The conditions of Theorem 3 hold for the feedback traders, so, according to Baumann (2015) resp. Theorem 3, their demand causes a bubble in the absence of any other traders. However, if fundamentalists enter the market, price explosion is prevented, as the demand rates tend to 0 at time $t=73$ in Table 2. Clearly, the conditions of Theorem 8 for feedback traders are not satisfied.

In summary, even a strong fundamentalistic demand rule, that is a strategy without any restrictions and involving a possibly infinitely large demand, is not able to stabilize the market when a trader using a very simple linear feedback strategy with an adequate initial investment is acting on the market, too. Market failures can happen, prices may explode, and the trading behavior of strong fundamentalists cannot prevent this. Note that our approach does not take into account the interactions between traders of the same type. These interactions might cause some emergent phenomena (Choi et al., 2001; Tesfatsion, 2002). Implicitly, we assume our agents to be representative for a certain type of traders on the market.

Table 1: The boxed table entries fulfill the conditions of Theorem 8 for $t=8$ for which prices explode; market parameters are as in Figure 7 (Note: $\ln 2 \approx 0.6931472$ ) $\left\{p_{0}=1, M=1, T=25, f_{t} \equiv 1, I_{0}^{C}=0.521, K=2\right\}$

\begin{tabular}{rrrrr}
\hline & $B_{t}^{C} \approx$ & $\Delta B_{t}^{C}=D_{t}^{C} \approx$ & $\Delta D_{t}^{C} \approx$ & $\Delta^{2} D_{t}^{C} \approx$ \\
\hline$t=0$ & $5.210000 \cdot 10^{-1}$ & $5.210000 \cdot 10^{-1}$ & $0.000000 \cdot 10^{0}$ & $0.000000 \cdot 10^{0}$ \\
$t=1$ & $1.233426 \cdot 10^{0}$ & $7.124264 \cdot 10^{-1}$ & $1.914264 \cdot 10^{-1}$ & $0.000000 \cdot 10^{0}$ \\
$t=2$ & $1.753872 \cdot 10^{0}$ & $5.204459 \cdot 10^{-1}$ & $-1.919805 \cdot 10^{-1}$ & $-3.834069 \cdot 10^{-1}$ \\
$t=3$ & $1.141150 \cdot 10^{0}$ & $-6.127224 \cdot 10^{-1}$ & $-1.133168 \cdot 10^{0}$ & $-9.411878 \cdot 10^{-1}$ \\
$t=4$ & $-4.062233 \cdot 10^{-1}$ & $-1.547373 \cdot 10^{0}$ & $-9.346507 \cdot 10^{-1}$ & $1.985175 \cdot 10^{-1}$ \\
$t=5$ & $8.715681 \cdot 10^{-2}$ & $4.933801 \cdot 10^{-1}$ & $2.040753 \cdot 10^{0}$ & $2.975404 \cdot 10^{0}$ \\
$t=6$ & $1.254431 \cdot 10^{0}$ & $1.167274 \cdot 10^{0}$ & $6.738944 \cdot 10^{-1}$ & $-1.366859 \cdot 10^{0}$ \\
$t=7$ & $3.667613 \cdot 10^{0}$ & $2.413181 \cdot 10^{0}$ & $1.245907 \cdot 10^{0}$ & $5.720125 \cdot 10^{-1}$ \\
\cline { 3 - 6 }$t=8$ & $2.183026 \cdot 10^{1}$ & $1.816265 \cdot 10^{1}$ & $1.574946 \cdot 10^{1}$ & $1.450356 \cdot 10^{1}$ \\
\cline { 3 - 5 }$t=9$ & $3.019914 \cdot 10^{8}$ & $3.019913 \cdot 10^{8}$ & $3.019913 \cdot 10^{8}$ & $3.019913 \cdot 10^{8}$ \\
\hline
\end{tabular}


Economics: The Open-Access, Open-Assessment E-Journal 13 (2019-44)

Table 2: The table shows a situation where the price would explode without fundamentalists but is stabilized by them. The investment parameters are the same as for Figure 5 where prices explode except that there additionally is a fundamentalist. The boxed cells fulfill the conditions required by Theorem 3

$$
\left\{p_{0}=1, M=1, T=250, f_{t} \equiv 1, I_{0}^{C}=0.192, K=2\right\}
$$

\begin{tabular}{rrrrr}
\hline & $B_{t}^{C} \approx$ & $\Delta B_{t}^{C}=D_{t}^{C} \approx$ & $\Delta D_{t}^{C} \approx$ & $\Delta^{2} D_{t}^{C} \approx$ \\
\hline$t=0$ & 0.1920000 & $1.920000 \cdot 10^{-1}$ & $0.000000 \cdot 10^{0}$ & $0.000000 \cdot 10^{0}$ \\
$t=1$ & 0.2732815 & $8.128148 \cdot 10^{-2}$ & $-1.107185 \cdot 10^{-1}$ & $0.000000 \cdot 10^{0}$ \\
$t=2$ & 0.2159966 & $-5.728489 \cdot 10^{-2}$ & $-1.385664 \cdot 10^{-1}$ & $-2.784784 \cdot 10^{-2}$ \\
$t=3$ & 0.1600990 & $-5.589755 \cdot 10^{-2}$ & $1.387332 \cdot 10^{-3}$ & $1.399537 \cdot 10^{-1}$ \\
$t=4$ & 0.1605436 & $4.445293 \cdot 10^{-4}$ & $5.634208 \cdot 10^{-2}$ & $5.495475 \cdot 10^{-2}$ \\
$\ldots$ & $\ldots$ & $\ldots$ & $\ldots$ & $\ldots$ \\
$t=73$ & 0.1788845 & 0 & 0 & 0 \\
\hline
\end{tabular}

\section{Discussion of effects of linear feedback trading}

Our analysis indicates that trend followers with bounded leverage may cause price explosions regardless of fundamentalists' investment decisions. Specifically, Theorem 8 and its proof analytically show that a fundamentalist's investment strategy, that is a strategy that pushes prices toward their fundamental values, can be insufficient to dominate linear feedback trading strategies. However, the potential for feedback traders' to create a bubble appears to be lower (Theorem 8) when fundamentalists are active in the market (cf. Theorem 3). Although the results indicate that fundamentalists have a stabilizing effect (cf. Table 2), this effect is limited up to some threshold value.

Given our results and the fact that financial bubbles are associated with high economic costs, an important question arises: seeing that fundamentalists do not appear to be an adequate market stabilizing force, is there another type of trader that would be able to stabilize prices in a marketappropriate way and, if so, what would such a trader look like? Generally, our analysis supports the view that intervention measures or at least some kind of incentive system is necessary to stabilize asset markets and prevent financial bubbles. Such measures could, for example, be the direct intervention of some regulatory or supervisory authority, progressive transaction costs, or trading restrictions.

Acknowledgements The work of Michael Heinrich Baumann was supported by Hanns-Seidel-Stiftung e.V. (HSS), funded by Bundesministerium für Bildung und Forschung (BMBF).

The authors thank Lars Grüne, Chair for Applied Mathematics, and Bernhard Herz, Chair of International Economics and Finance, both with University of Bayreuth, for discussing the results, supervising the work, and revising the paper. The authors also thank Deborah Willow, WillowHut Publishing Services, for revising the work. Furthermore, the authors thank all referees and editors for their helpful comments.

Parts of the analysis have been used in the doctoral thesis of Michael Heinrich Baumann (Baumann, 2018).

This paper was presented at the XVIII. Workshop on Quantitative Finance 2017 (QFW2017), University of MilanoBicocca, Milano, Italy, at the XVI. Annual European Economics and Finance Society Conference 2017 (EEFS2017) at University of Ljubljana, Ljubljana, Slovenia, and at the 49th Money, Macro and Finance Research Group Annual Conference 2017 (MMF2017), King's Business School, King's College London, Strand, London, UK. 


\section{References}

Barmish, B. R., and Primbs, J. A. (2011). On Arbitrage Possibilities via Linear Feedback in an Idealized Brownian Motion Stock Market. In IEEE Conference on Decision and Control and European Control Conference (CDC-ECC), pages 2889-2894. URL http://dx.doi.org/10.1109/CDC.2011.6160731.

Barmish, B. R., and Primbs, J. A. (2016). On a New Paradigm for Stock Trading Via a Model-Free Feedback Controller. IEEE Transactions on Automatic Control, 61(3): 662-676. URL http://dx.doi.org/10.1109/TAC.2015.2444078.

Baumann, M. H. (2015). Effects of Linear Feedback Trading in an Interactive Market Model. In American Control Conference (ACC), pages 3880-3885. URL http://dx.doi.org/10.1109/ACC.2015.7171935.

Baumann, M. H. (2017). On Stock Trading via Feedback Control when Underlying Stock Returns are Discontinuous. IEEE Transactions on Automatic Control, 62(6): 2987-2992. URL http://dx.doi.org/10.1109/TAC.2016.2605743.

Baumann, M. H. (2018). Performance and Effects of Linear Feedback Stock Trading Strategies. Dissertation, University of Bayreuth, Faculty for Mathematics, Physics and Computer Science. URL https://eref.uni-bayreuth.de/id/eprint/ 46044.

Baumann, M. H., and Grüne, L. (2017). Simultaneously Long Short Trading in Discrete and Continuous Time. Systems \& Control Letters, 99: 85-89. URL http://dx.doi.org/10.1016/j.sysconle.2016.11.011.

Baumann, M. H., and Grüne, L. (2019). Positive Expected Feedback Trading Gain for all Essentially Linearly Representable Prices. In Asian Control Conference (ASCC), pages 150-155. URL https://ieeexplore.iee.org/ document/8765015.

Beker, V. A. (2010). On the Economic Crisis and the Crisis of Economics. Economics Discussion Papers, Kiel Institute for the World Economy, 2010-18. URL http://www.economics-ejournal.org/economics/discussionpapers/2010-18. Discussion Paper.

Biondo, A. E. (2018). Learning to Forecast, Risk Aversion, and Microstructural Aspects of Financial Stability. Economics: The Open-Access, Open-Assessment E-Journal, 2018-20(12): 1-20. URL http://dx.doi.org/10.5018/ economics-ejournal.ja.2018-20.

Black, F. (1986). Noise. Journal of Finance, 41(3): 529-543. URL http://dx.doi.org/10.1111/j.1540-6261.1986.tb04513. $\mathrm{x}$.

Bormann, S.-K. (2013). Sentiment Indices on Financial Markets: What Do they Measure? Economics Discussion Papers, Kiel Institute for the World Economy, 2013-58. URL http://www.economics-ejournal.org/economics/discussionpapers/ 2013-58. Discussion Paper.

Bornholdt, S. (2001). Expectation Bubbles in a Spin Model of Markets: Intermittency from Frustration Across Scales. International Journal of Modern Physics C, 12(05): 667-674. URL http://dx.doi.org/10.1142/S0129183101001845.

Brock, W. A., and Hommes, C. H. (1997). A Rational Route to Randomness. Econometrica, 65(5): 1059-1095. URL https://doi.org/10.2307/2171879.

Brock, W. A., and Hommes, C. H. (1998). Heterogeneous Beliefs and Routes to Chaos in a Simple Asset Pricing Model. Journal of Economic Dynamics and Control, 22(8): 1235-1274. URL https://doi.org/10.1016/S0165-1889(98) 00011-6.

Caccioli, F., and Marsili, M. (2010). Information Efficiency and Financial Stability. Economics: The Open-Access, Open-Assessment E-Journal, 2010-20(4): 1-20. URL http://dx.doi.org/10.5018/economics-ejournal.ja.2010-20.

Choi, T. Y., Dooley, K. J., and Rungtusanatham, M. (2001). Supply Networks and Complex Adaptive Systems: Control Versus Emergence. Journal of Operations Management, 19(3): 351-366. URL https://doi.org/10.1016/ S0272-6963(00)00068-1. 
Covel, M. (2004). Trend Following: How Great Traders Make Millions in Up or Down Markets. FT Press, 1 st edition.

da Gama Batista, J., Massaro, D., Bouchaud, J.-P., Challet, D., and Hommes, C. (2017). Do Investors Trade Too Much? A Laboratory Experiment. Journal of Economic Behavior \& Organization, 140(C): 18-34. URL http: //dx.doi.org/10.1016/j.jebo.2017.05.013.

Day, R. H., and Huang, W. H. (1990). Bulls, Bears and Market Sheep. Journal of Economic Behavior \& Organization, 14(3): 299-329. URL https://doi.org/10.1016/0167-2681(90)90061-H.

De Long, J. B., Shleifer, A., Summers, L. H., and Waldmann, R. J. (1990a). Noise Trader Risk in Financial Markets. Journal of Political Economy, 98(4): 703-738. URL https://www.jstor.org/stable/2937765.

De Long, J. B., Shleifer, A., Summers, L. H., and Waldmann, R. J. (1990b). Positive Feedback Investment Strategies and Destabilizing Rational Speculation. Journal of Finance, 45(2): 379-395. URL https://www.jstor.org/stable/2328662.

Demary, M. (2010). Transaction Taxes and Traders with Heterogeneous Investment Horizons in an Agent-Based Financial Market Model. Economics: The Open-Access, Open-Assessment E-Journal, 2010-8(4): 1-44. URL http://dx.doi.org/10.5018/economics-ejournal.ja.2010-8.

Dieci, R., and Westerhoff, F. (2010). Heterogeneous Speculators, Endogenous Fluctuations and Interacting Markets: A Model of Stock Prices and Exchange Rates. Journal of Economic Dynamics and Control, 34(4): 743-764. URL https://doi.org/10.1016/j.jedc.2009.11.002.

Drescher, C., and Herz, B. (2012). Monetary Shocks in Bounded Efficient Financial Markets with Bounded Rational Agents. Discussion Paper 09-12, Wirtschaftswissenschaftliche Diskussionspapiere. URL http://www.fiwi. uni-bayreuth.de/de/download/WP_09-12.pdf.

Franke, R., and Westerhoff, F. (2012). Structural Stochastic Volatility in Asset Pricing Dynamics: Estimation and Model Contest. Journal of Economic Dynamics and Control, 36(8): 1193-1211. URL http://dx.doi.org/10.1016/j.jedc.2011. 10.004 .

Franke, R., and Westerhoff, F. (2016). Why a Simple Herding Model May Generate the Stylized Facts of Daily Returns: Explanation and Estimation. Journal of Economic Interaction and Coordination, 11(1): 1-34. URL https://link.springer.com/article/10.1007/s11403-014-0140-6.

Gaunersdorfer, A., and Hommes, C. (2007). A Nonlinear Structural Model for Volatility Clustering. In G. Teyssière, and A. P. Kirman (Eds.), Long Memory in Economics, pages 265-288. Springer Berlin Heidelberg. URL https: //link.springer.com/chapter/10.1007/978-3-540-34625-8_9.

Graham, B., Dodd, D. L. F., and Cottle, S. (1934). Security Analysis. New York: McGraw-Hill.

Hermsen, O., Witte, B.-C., and Westerhoff, F. (2010). Disclosure Requirements, the Release of New Information and Market Efficiency: New Insights from Agent-based Models. Economics: The Open-Access, Open-Assessment E-Journal, 2010-7(4): 1-26. URL http://www.economics-ejournal.org/economics/journalarticles/2010-7.

Hommes, C. H. (2002). Modeling the Stylized Facts in Finance Through Simple Nonlinear Adaptive Systems. Proceedings of the National Academy of Sciences of the United States of America, 99(4): 7221-7228. URL http://www.pnas.org/content/99/suppl_3/7221.

Hommes, C. H. (2006a). Heterogeneous Agent Models in Economics and Finance. In L. Tesfatsion, and K. L. Judd (Eds.), Handbook of Computational Economics, Volume 2, pages 1109-1186. Elsevier. URL http://dx.doi.org/10. 1016/S1574-0021(05)02023-X.

Hommes, C. H. (2006b). Interacting Agents in Finance. Tinbergen Institute Discussion Paper No. 06-029/1. URL https://papers.ssrn.com/sol3/papers.cfm?abstract_id=894221. 
Huang, W. H., and Day, R. H. (1993). Chaotically Switching Bear and Bull Markets: the Derivation of Stock Price Distributions from Behavioral Rules. Nonlinear dynamics and evolutionary economics, pages 169-182.

Ivanova, Y., Neely, C. J., Rapach, D. E., and Weller, P. A. (2014). Can Risk Explain the Profitability of Technical Trading in Currency Markets? Federal Reserve Bank of St. Louis Working Paper Series, 2014-033(A). URL http://dx.doi.org/10.20955/wp.2014.033.

Kim, G.-r., and Markowitz, H. M. (1989). Investment Rules, Margin, and Market Volatility. The Journal of Portfolio Management, 16(1): 45-52. URL https://doi.org/10.3905/jpm.1989.409233.

Krug, S. (2018). The Interaction between Monetary and Macroprudential Policy: Should Central Banks 'Lean against the Wind' to Foster Macro-Financial Stability? Economics: The Open-Access, Open-Assessment E-Journal, 2018-7(12): 1-69. URL http://dx.doi.org/10.5018/economics-ejournal.ja.2018-7.

Lux, T. (1995). Herd Behaviour, Bubbles and Crashes. Economic Journal, 105(431): 881-896. URL http://dx.doi.org/ $10.2307 / 2235156$.

Lux, T. (1998). The Socio-Economic Dynamics of Speculative Markets: Interacting Agents, Chaos, and the Fat Tails of Return Distributions. Journal of Economic Behavior \& Organization, 33(2): 143-165. URL http://dx.doi.org/10. 1016/S0167-2681(97)00088-7.

Lux, T., and Marchesi, M. (1999). Scaling and Criticality in a Stochastic Multi-Agent Model of a Financial Market. Nature, 397: 498-500. URL https://www.nature.com/articles/17290.

Lux, T., and Marchesi, M. (2000). Volatility Clustering in Financial Markets: A Microsimulation of Interacting Agents. International Journal of Theoretical and Applied Finance, 3(4): 675-702. URL http://dx.doi.org/10.1016/ S1474-6670(17)40450-2.

Primbs, J. A., and Barmish, B. R. (2013). On Stock Trading: Can a Trend Follower Expect to Win? In SSRN Electronic Journal. Midwest Finance Association Conference. URL http://dx.doi.org/10.2139/ssrn.2154591.

Primbs, J. A., and Barmish, B. R. (2017). On Robustness of Simultaneous Long-Short Stock Trading Control with Time-Varying Price Dynamics. IFAC-PapersOnLine, 50(1): 12267 - 12272. URL http://dx.doi.org/10.1016/j.ifacol. 2017.08.2045. 20th IFAC World Congress.

Schasfoort, J., and Stockermans, C. (2017). Fundamentals Unknown: Momentum, Mean-Reversion and Price-toEarnings Trading in an Artificial Stock Market. Economics Discussion Papers, Kiel Institute for the World Economy, 2017-63. URL http://www.economics-ejournal.org/economics/discussionpapers/2017-63. Discussion Paper.

Tesfatsion, L. (2002). Economic Agents and Markets as Emergent Phenomena. Proceedings of the National Academy of Sciences, 99(suppl 3): 7191-7192. URL https://doi.org/10.1073/pnas.072079199.

Tramontana, F., Gardini, L., Dieci, R., and Westerhoff, F. (2009). The Emergence of "Bull and Bear" Dynamics in a Nonlinear Model of Interacting Markets. Discrete Dynamics in Nature and Society. URL https://doi.org/10.1155/ $2009 / 310471$.

Tramontana, F., Gardini, L., Dieci, R., and Westerhoff, F. (2010). Global Bifurcations in a Three-Dimensional Financial Model of Bull and Bear Interactions, pages 333-352. Springer Berlin Heidelberg. URL https://doi.org/10.1007/ 978-3-642-04023-8_18.

Westerhoff, F. H. (2004). Speculative Dynamics, Feedback Traders and Transaction Taxes: A Note, volume 55. Univ., Fachbereich Wirtschaftswiss. URL https://www.uni-bamberg.de/fileadmin/uni/fakultaeten/sowi_lehrstuehle/vwl_ wirtschaftspolitik/Team/Westerhoff/Publications/2004/2004_Pbl_Westerhoff.pdf.

Westerhoff, F. H. (2006a). Nonlinear Expectation Formation, Endogenous Business Cycles and Stylized Facts. Studies in Nonlinear Dynamics \& Econometrics, 10(4). URL http://dx.doi.org/10.2202/1558-3708.1324. 
Westerhoff, F. H. (2006b). Samuelson's Multiplier-Accelerator Model Revisited. Applied Economics Letters, 13(2): 89-92. URL https://www.uni-bamberg.de/fileadmin/uni/fakultaeten/sowi_lehrstuehle/vwl_wirtschaftspolitik/Team/ Westerhoff/Publications/2006/2006_Pbl_Westerhoff_II.pdf.

Westerhoff, F. H. (2007). On Central Bank Interventions and Transaction Taxes. Applied Financial Economics Letters, 3(1): 11-14. URL https://www.uni-bamberg.de/fileadmin/uni/fakultaeten/sowi_lehrstuehle/vwl_wirtschaftspolitik/ Team/Westerhoff/Publications/2007/2007_Pbl_Westerhoff.pdf.

Westerhoff, F. H., and Dieci, R. (2006). The Effectiveness of Keynes-Tobin Transaction Taxes when Heterogeneous Agents Can Trade in Different Markets: A Behavioral Finance Approach. Journal of Economic Dynamics and Control, 30(2): 293-322. URL http://dx.doi.org/10.1016/j.jedc.2004.12.004. 


\section{Economics}

Please note:

You are most sincerely encouraged to participate in the open assessment of this article. You can do so by either recommending the article or by posting your comments.

Please go to:

http://dx.doi.org/10.5018/economics-ejournal.ja.2019-44

The Editor 